\title{
EL CONCEPTO DE MUNICIPIO Y CONSIGUIENTE DEFINICION
}

\begin{abstract}
Con
OMO síntesis de cualquier concepto, y expresión abreviada de sus notas características y diferencias, es bien difícil lograr una exacta definición, y más todavía si el concepto ha de acusar y recoger, en alusión, por lo menos, aspectos sociales, históricos y jurídicos, como es el caso en el Municipio. Naturalmente, cabe omitir la definición; pero si esta excusa es posible en el terreno de la ley positiva, no lo es en el intelectivo, lógico y mental, en que la tendencia es siempre convertir el análisis descriptivo en síntesis conceptual. Desde el primer punto de vista puede esquivarse la dificultad, dándola por científicamente resuelta; pero en el campo doctrinal no hay escape: es bien enérgica la tendencia a la definición, y, más todavía: si no hay definición, suprimimos el instrumento adecuado para toda clase de investigaciones, $y$ hasta se tropezaría con la dificultad del lenguaje, que, formado de palabras, exige en éstas un significado más o menos preciso, pero con un valor determinado de antemano.

En cuanto a la definición de Municipio, cuyo es el objeto de este trabajo, tratadistas bien eminentes denunciaron cuán difícil era de lograr. Así, en Alemania, Stein, así Rehmb así Jellinek. Con estos antecedentes doctrinales, no es extraño que en el país citado se haya esquivado la dificultad al dictarse la ley municipal de 30 de enero de 1935 , porque no se puede decir que haya definición ni en su artículo $1 .^{\circ} \mathrm{ni}$ en su artículo $9 .^{\circ}$, ya que aquél se limita a insertar unas cualidades, y el segundo, a proclamar un hecho. He aquí los textos citados:
\end{abstract}

Art. 1.9 1) Los Municipios reúnen las energías del pueblo existentes en la comunidad local para alcanzar los fines públicos de la patria menor.

2) Los Municipios son corporaciones públicas territoriales... 
Art. 9.2 1) Son ciudades los Municipios que llevan en la actualidad tal denominación. (Los dos párrafos, tan modernos en su expresión, evocan las reflexiones de Stein, previas a su concepto de Municipio.)

Tales conceptos rehuyen el problema; no puede decirse que expresen una definición bien que acaso tampoco se lo propuso el legislador.

Quizá con mayor osadía, y olvidando aquel viejo principio, latino también, que declaraba peligrosa toda definición, nosotros, los pueblos latinos, propendemos a definir, y no sólo doctrinalmente, sino también al formular leyes, propensión de que no se ha librado el $\mathrm{Mu}$ nicipio. (Portugal es una excepción. Más bien en este particular se inclina al tipo alemán: "Es Concejo el agregado de personas que residen en un término municipal y tienen intereses comunes... El Concejo, con sus órganos propios, es persona moral de derecho público." Código Administrativo de 31 de diciembre de 1936, artículos 13 y 14.) No vale la pena de recogerlas; será bastante trasladar las dos que se copian; una de Ferraris, como muestra doctrinal, y las españolas de sus leyes como ejemplo de expresión jurídica positiva.

Ferraris, La administración local en Italia, pág. 357, formula la siguiente definición de Municipio: "Pequeña circunscripción administrativa autárquica, con territorio y población propios, dotada de personalidad, que dentro del derecho objetivo ejerce poder de imperio y dispone de facultades discrecionales, con funcionarios honorarios designados por elección popular, bajo la vigilancia del Estado, coordinando sus funciones con las de la Administración gubernamental, y recaudanđo por sí los fondos necesarios." La crítica de esta definición exigiría más líneas de las que se le pueden dedicar aquí, ya que habría que analizar desde la primera frase, inquiriendo cuándo una circunscripción es pequeña, si es esencial que tenga funcionarios honorarios y que éstos sean designados precisamente por elección popular, hasta la última, pues no se advierte claramente que sea típico del Municipio la recaudación de sus fondos. Esos conceptos pueden, en todo caso, aplicarse a cualquier otra entidad territorial, y por lo tanto, por lo menos, contra la expresión de Ferraris, habría que decir que las que él da no son características diferenciales del Municipio, aunque puedan atribuirse a todo Municipio; es decir, podríamios, a todo conceder, admitir que no hay $\mathrm{Mu}$ nicipio si no se insertan en él aquellas cualidades; pero que de su concurrencia en una entidad determinada no se sigue que esta entidad sea un Municipio. 
Doctrinalmente, me parece más correcta y real, más exacta y precisa, sobre ser más clara y breve, la definición del ilustre profesor español don Adolfo Posada: "Municipio supone, en su origen, y en los momentos de mayor florecimiento del régimen municipal, la situación de un pueblo con personalidad propia jurídicamente reconocida, y, a la vez, contenido en un régimen político más amplio y. superior-sometido a un imperium". Con pocas modificaciones, y éstas de matiz, esa definición sería plenamente aceptable, y no sólo, como parece intentarse, para referida a un momento histórico y pasado, sino también al presente y de hoy.

Veamos ahora las definiciones que se incorporaron a nuestra legislación. La ley de 2 de octubre de 1877 (como se sabe, esta fecha es la de su última refundición; pero la ley, en el punto que nos interesa, venía muy de atrás), en el art. 1.9 decía: "Es Municipio la asociación legal de todas las personas que residen en un término municipal". Lo esencial, como se ve, es el término municipal; si éste se suprime, desaparece la masa de personas legalmente asociadas. $Y$ viene a resultar que el territorio es el determinante de la personalidad, lo cual es absurdo; y además, lo que no es lógico, tenemos un término municipal sin Municipio previo que exija el término. Aparte estos reparos, es cierto que en el Municipio, una vez constituído, hay una asociación legal de personas y un asiento territorial; en todo Municipio, ya lo veremos, ha de haber eso; pero ha de haber algo más, si ha de ser Municipio. Incluso para la ley misma, no siem pre con esas circunstancias hay Municipio; y con solas esas circunstancias tampoco lo hay. La primera afirmación se comprueba sin más que transcribir el art. 90 de la citada ley municipal, que dice así: "Los pueblos que, formando con otro término municipal, tengan territorio propio (el territorio propio se diferencia del término municipal del cual es integrante), asuas, pastos, montes o cualquiera derechos que les sean peculiares, conservarán sobre ellos su administración particular". Art. 91: "Para dicha administración nombrarán una Junta...". Por 10 tanto, estos pueblos tienen un territorio, tienen una masa de población, tienen una Junta, como los Municipios, sin más qui, cambiar las denominaciones, y son... pueblos agregados a un térinino municipal, no Municipios.

Que tampoco es bastante la asociación y el territorio, lo comprueba el art. $2 .^{\circ}$ de la ley, que exige a la asociación y al territorio, para que determinen la constitución de un Municipio, ciertas circunstancias cuantitativas; éstas: $10^{\text {. }}$ Que no bajen de 2.000 el número de sus habitantes residentes. 2." Que tenga o se le pueda señalar un 
territorio proporcionado a su población. 3. ${ }^{2}$ Que pueda sufragar los gastos municipales obligatorios con los recursos que las leyes autorizan. Como excepción, pero expresamente señalada, el párrafo último del artículo mencionado agrega: "Subsistirán, sin embargo, los actuales términos municipales que tengan Ayuntamiento, aun cuando no reunan las circunstancias anteriores", reserva ésta que se halla también en la legislación posterior.

Pasemos al Estatuto Municipal. Rompe el texto con la definición de Municipio: "Art. 1. ${ }^{\circ}$ Es municipio la asociación natural, reconocida por la ley, de personas y bienes, determinada por necesarias relaciones de vecindad, dentro del término a que alcanza la jurisdicción de un Ayuntamiento". También esta definición sugiere en masa los reparos. Calificando el Municipio de asociación natural, ya se incurre en el primer defecto, porque ninguna asociación natural puede ser Municipio, toda vez que Municipio es una cualidad jurídica, y ésta no se desprende de la naturaleza, sino del Estado. Además, contraponiendo esa asociación natural al reconocimiento por la ley, parece al pronto que para la ley es forzoso el reconocimiento, y esto se quiere decir; pero como el Municipio no es natural, como es una consecuencia del derecho y de la ley, ésta le reconoce o no, le atribuye aquella cualidad, o la sustrae, incluso en el propio Estatuto, en el cual, con inconsecuencia respecto de la definición, pero en lógica correspondencia con la realidad, llega a autorizar la supresión de Municipios y a exigir condiciones para su creación.

No porque sean necesarios datos, pues el hecho es harto conocido; pero sí para que se aprecie su frecuencia, diremos que desde 1920 a 1927, es decir, bajo la vigencia de la ley de 1877 y de la del Estatuto de 1924, se suprimieron 48 Municipios y se crearon 32. De los primeros, 32 se suprimieron simple y llanamente, y 16 desaparecieron por fusión. De los creados, 35 se erigían ahora en $\mathrm{Mu}$ nicipios, y siete resultaban de aquellos 16 fusionados. Uno de los nacidos por fusión absorbia cuatro.

El propio Estatuto, como la ley de 1877, exigía en su art. 16 determinadas condiciones para constituir nuevo Municipio: 1.; que los Municipios de origen lo autoricen; $2 .{ }^{2}$, que no reduzcan su solvencia; $3 .^{a}$, que ni los de origen ni el nuevo carezcan de los medios necesarios para el cumplimiento de sus fines. $Y$, a pesar de la naturalidad del Municipio, se ve obligado a buscar otra: la verdaderamente social: el pueblo (art. 38 y otros varios), la misma que se adoptó por los legisladores de Cádiz. 
El reconocimiento por la ley es frase que sustituye a la idea de Estado, frente al cual se alza el Municipio en la definición del Estatuto. Así lo dice claramente la exposición de motivos del Estatuto Municipal: "El Municipio... no es hijo del legislador: es un hecho social de convivencia, anterior al Estado y anterior también, y, además, superior, a la ley. Esta ha de limitarse, por tanto, a reconocerlo y ampararlo en función adjetiva". Pero se confunde, como es tan frecuente, causando la ofuscación que se padece en estos particulares, no obstante ser tan claros y hasta elementales, el hecho social con el hecho jurídico, sin ver que el Municipio no es un hecho social, sino, precisamente, un hecho jurídico; lo social y natural, natural en cuanto la fuerza atractiva y aglutinante del grupo, puede ser extraño a toda precisión jurídica y obedecer a razones geográficas, de expansión familiar, mercantiles, económicas o productoras..., es la agrupación urbana, llámese aldea o ciudad, la cual bien puede ser, en cuanto al tiempo, anterior al Estado; pero tampoco a todo Estado, sino a uno concreto e histórico, por ejemplo, al Estado Nacional. En tal sentido, valga la definición de San Agustín: "La ciudad es multitud de hombres coligada entre sí con ciertol vínculo de sociedad" (La Ciudad de Dios, libro XV, cap. VIII.)

La definición del Estatuto Municipal destaca una cualidad, no nueva, pero sí de interés: las relaciones de vecindad. Procede de la ley cubana de 29 de mayo de 1908, que sustituyó a la nuestra de 1877. La cubana dice así: "Para los efectos de esta ley, el Municipio es la sociedad legal, organizada políticamente, con autorización del Poder Legislativo Nacional, y comprendida dentro de una extensión superficial, naturalmente determinada por necesarias relaciones de vecindad". Ya se ve que, efectivamente, la frase se importa al Estatuto Municipal desde la ley cubana, obra ésta del ilustre municipalista Carrera y Justiz. Pero valga aquí una digresión para reivindicar el origen español de esas palabras, pues de España proceden. Don Alejandro Oliván, en 1843, publicó su obrita De la Administración..., en la cual, pág. 103, definía el Municipio como "aglomeración de hombres relacionados por la vecindad..."; de lazos de vecindad hablaba Colmeiro; y aún la expresión se generalizó y apareció acogida en obras generales de Derecho. Sin embargo, ninguno de los proyectos españoles que precedieron al Estatuto utilizó la expresión, que trasladó a Cuba el escritor mencionado en sus Instituciones Sociales..., hablando en ellas de vecindad, comb hablaba también de lares y de relación. 
Volvamos ya a nuestra exposición. En lo sustancial, la ley de 31 de octubre de 1935, art. 2. $.^{\circ} \S 1 .^{\circ}$, repite los conceptos mismos del Estatuto: "El Municipio es una asociación natural de carácter público de personas y bienes, constituído por necesarias relaciones de vecindad y domicilio dentro de un territorio determinado". Reitérase aquí el concepto asociación utilizado en el Estatuto, probablemente el menos adecuado y oportuno de cuantos se pudieran emplear, ya que asociación suscita la idea de ley previa que sirva de base a aquélla, aunque se hubiera podido utilizar, por ejemplo, la voz, comuni dad, que suena a hecho aglutinante más espontáneo; la vecindad se complica ahora con el domicilio, sin ver que si en la primera cabe una acepción natural, extralegal, la segunda suena a mayor refinamiento, a sentido jurídico, y, por lo tanto, poco natural, siendo así que esto, lo natural, lo espontáneo, es lo que se busca.

Pues bien, si nosotros recogemos las características de estas definiciones: asociación natural, relaciones de vecindad, asiento territorial, tendremos derecho a repetir la cualidad de Municipio donde quiera que las hallemos. Sin embargo, no es así, ni para el Estatuto Municipal, ni para la ley de 1935, como, según vimos, no lo fué para la de 1877. Las aldeas, parroquias, lugares, agregados, que constituyen núcleos independientes de población o de edificaciones, con territorio propio e intereses peculiares, no obstante constituir una asociación natural, mantener unas relaciones de vecindad y disponer de su territorio, no son Municipios; son Entidades locales menores. Por cierto, que hace esto quebrar las relaciones de vecindad como característica del Municipio, ya que se darán dentro de la Entidad y dentro del grupo a que se atribuya la capitalidad municipal, pero no entre uno y otro grupo. Ni es fácil. Citemos ahora el caso de La Estrada (Pontevedra), cuya población (en 1920) alcanzaba a 25.471 habitantes, distribuídos en 57 pueblos, algunos separados del pueblo-capital más de 15 kilómetros. Casos análogos se dan en Murcia, en Cartagena y en Lorca. ¡Buenas relaciones de vecindad!

Al ilustre autor del Estatuto no podían pasarle inadvertidas estas alegaciones, y se adelantaba a contestarlas en la exposición de motivos ya antes citada: "...la convivencia se da en núcleos de gradación ilimitada, desde los insignificantes, que sólo constan de unas cuantas docenas de vecinos, hasta los gigantescos... Y no sólo tienen carácter vecinal los Municipios propiamente dichos: lo tienen tamr bién las Entidades menores o fracciones de Municipio... (nótese la contradicción)... Por todo ello, el nuevo Estatuto admite la personalidad 
municipal allí donde la Naturaleza lo engendra... y admite también la de los... demás grupos menores de población...".

Pero son Entidades, no Municipios; es del Estatuto de quien reciben su personalidad... Y la prueba está, todavía, en que ni basta el hecho de la existencia, como ocurre con la Parroquia, que ha de reconocerse por su Ayuntamiento, y, a lo menos, llevar dos años de existencia, si durante ese tiempo, aún no siendo Parroquia en la acepción eclesiástica de la palabra, disfruta de delegaciones parroquiales. (R. O. 13 julio 1926.)

De modo que, por expresa declaración de la ley, tenemos núcleos urbanos o agrupaciones que no son Municipios; y, en efecto, así es en España, con nomenclatura variada y múltiple de difícil caracterización: Ciudades y Villas, meras denominaciones de honor; los pagos, o formaciones rurales de Canarias unidas a un núcleo urbano principal; aldeas, edificaciones en torno a un cultivo, sin jurisdicción propia e integrante de un Ayuntamiento; caseríos, caserías, anteiglesias, en las provincias vascongadas; lugares, o agrupación de aldeas; parroquias, o agrupación de lugares...

Todas éstas son las formaciones sociales, los grupos, unitarios o compuestos, conjuntos o dispersos, base material y económica de origen espontáneo y natural, que luego son o no Municipios. Que lleguen a serlo, que lleguen a alcanzar tal condición por conversión en normas jurídicas de sus previas costumbres jurídicas, puede ser, lo será casi siempre; pero en cuanto Municipio, ya no es un hecho natural, sino un hecho jurídico. Lo natural, lo social, lo espontáneo, es la reunión en la confluencia de unos ríos, o en el cruce de los caminos, o bajo los castaños del ferial, o al amparo del castillo, o bajo la protección del convento; pero no el Municipio. El Municipio es un concepto jurídico, y además relativo, no absoluto. El propio hecho justifica su doble calificación. La voz. Municipio presupone un núcleo urbano, pero no equivale a núcleo urbano; designa una cualidad jurídica, una investidura, una plenitud. Si ésta es originaria y aislada, sin otra superior, no es Municipio, es Estado; y si hay Estado o cima jurídica comprensiva y soberana, es éste la fuente jurídica del Municipio. Por lo tanto, la voz Municipio es un concepto jurídico, como expresa su propia etimología (municipium se forma de muni y cepit; munis o munus, ri, que significa oficio u obligación pública; y cepit, de capere, tomar o poseer. Por lo tanto, municipio $=$ municipium $=$ munum cepit $=$ el o lo que posee una obligación pública), y expresa su adherencia a un núcleo integrante, sometido, 
subordinado al Estado. Cuando en Roma se disgregan los dos conceptos: ciudad-civitas-res publicae-del Estado, éste recibe un nuevo nombre: imperium: poder soberano. Mommsen definió el $\mathrm{Mu}$ nicipio: "derecho de la ciudad dentro del Estado".

En cuanto envolvente de un cierto núcleo social, y éste formado o por expansión de su célula originaria, la familia, o por sucesivas adiciones a ella o incorporaciones, es decir, nacido de fuerzas y actividades ingénitas, propias, interiores, que se expansionan o que atraen capas sucesivas, puede decirse del Municipio que es natural, que nace de sí mismo, con tal de que en todo momento se advierta de que los términos-grupo, Municipio-no son equivalentes, ni intercambiables, ni recíprocos, ya que, si todo Municipio presupone un núcleo social, digamos para darle una denominación, urbano, la inver'sa no es cierta, $y$ no todo núcleo urbano implica o exige un Municipio. Por donde, volviendo al punto de partida, hallamos de nuevo que el Municipio, en cuanto originado exteriormente por fuerzas extrañas, ajenas al propio núcleo que se deriva e inviste de $\mathrm{Mu}$ nicipio, no es natural. Así vemos que ,lejos de ir fundidas, recíprocamente penetradas, con frecuencia se disocian y separan el supuesto social del revestimiento jurídico, hasta el punto de que la cualidadl jurídica ni siquiera, de existir, califica a un grupo simple, elemental, a una unidad urbana, sino que una pluralidad urbana, una variedad de grupos, aunque cada uno nazca de sí mismo en el aspecto social, son soporte conjuntamente, de modo compuesto, de la unidad jurídica municipal. Por lo tanto, Municipio acaba por significar una cualidad jurídica, una personalidad jurídica, de uno o varios grupos urbanos; y como esa cualidad, según queda dicho, no es consecuencia de fuerza alguna interna, ha de provenir del exterior, de otra fuerza externa, que el desarrollo ampliatorio sucesivo: familia, gens, tribu, ciudad... va adicionando el calificativo de jurídico, y las facultades, potestades, atribuciones que se insertan en el mismo. Sin este aditamento exterior, la evolución social, el crecimiento interno, no tropieza nunca con un punto de desarrollo que se llame o sea Municipio. Es natural, la evolución de la ciudad, que cuando aislada y soberana se llama Estado; y cuando, equiparada a otras, pierde su propia soberanía, la ciudad cristaliza en Municipio... o no. Se produce así la metrocomía; y sobre la metrocomía, el synecismo, hace, socialmente, la nación; jurídicamente, el Estado. Con la palabra griega metrocomía-de méter o metra-madre o matriz - home, aldea, lugẫr-se designa un conjunto de capital o villa principal y de varias aldeas, barrios, caseríos o lugares, asentados en el 
distrito de aquélla y a ella unidas (en Roma, la palabra tuvo otra acepción que aquí no interesa), a la manera de nuestros medievales alfozes; régimen, por lo tanto, distinto del que suponían en Grecia sus anficcionías o federaciones, que tampoco, en puridad, creaban una unidad jurídica superior, puesto que no sólo mantenían la independencia de los elementos componentes, sino que precisamente se constituían como lazos de comunicación tendidos siempre en el supuesto autonómico y valorando los elementos componentes, que lo eran las ciudades-Estados, soberanas; no ciudades-Municipios, subordinadas.

Luego vendrá el synekismo, la atracción fusionadora de grupos, la ulterior unidad compuesta, que también en Grecia ha operado en la formación de la ciudad, pues si ésta-lo que hoy es para nosotros difícil de comprender-significa una unidad (que tampoco lo es social: Gran París, Gran Berlín...), es jurídica precisamente, no social, ya que mantienen sus caracteres propios las tribus componentes.

En esta diferencia de grado o jerarquía radica la que puede establecerse doctrinalmente entre Estado y Municipio, no de otra manera, puesto que ambas instituciones tienen los propios elementos (Stein), o bien, el Municipio es un Estado pequeño dentro de otro grande (Vivien), o análogo al Estado (Mayer), o su paradigma (Jellinek), o su microcosmos (Marchi).

Una forma de soberanía ejercita el Municipio en sus funciones de policía, en la recaudación de sus impuestos, en la imposición de prestaciones personales obligatorias. Ahora bien, esas facultades, 0 dígase poderes, ¿dimanan del Municipio mismo, o el Municipio que las ejercita las recibe del Estado? Se ha hablado de un poder municipal, en Francia por Benjamín Constant, en España por Joaquín María López. No hemos de hacer una exposición sobre la evolución que da por resultado tales conceptos, ni es necesario, pues, en lo suficiente, se encuentra ya en la clásica monografía de Jellinek, sobre los Derechos subjetivos (XVII). La constitución de un Estado significa la sustracción del imperium a la entidad antecesora, a la ciudad, si es ella. Por lo tanto, la ciudad pierde el imperium, pierde la cuar lidad de Estado, y si mantiene una plenitud jurídica, ésta se hallará condicionada por la del imperium, es decir, entonces nacerá el nombre de Municipio. Por eso, no sólo el Municipio se da en el Estado, sino que fuera del Estado, no puede ni concebirse, y su posible concepción no puede ser más que a título de órgano del Estado.

También la historia comprueba esto, incluso en España. Que las ciudades primitivas españolas fueran Estados, ya se sostuvo por 
Pérez Pujol, y es reiterado por Schulten, ya que en las guerras intervenían aisladamente, con independencia, usaban de moneda propia, y se citan en los textos literarios de la época como patria. Schulten, en Hispania, escribe literalmente: "La unidad política no es la tribu, como entre los celtas y los germanos, sino, como entre los bereberes, la ciudad y el castillo... No sólo las ciudades grandes, sino también las pequeñas y los más pequeños castillos, son comunidades políticas... Por esto, ningún país tiene tantas comunidades políticas como España." A la cabeza de estas ciudades hay un Senado, y su jefe es un rey o un general. Hay tribus sobre las ciudades, pero esa unidad superior lo es etnológica. solamente, no política.

$\mathrm{Y}$ es todo natural y fácilmente explicable. La conjunción, coin cidencia, convivencia, traban y provocan necesidades comunes y generales, positivas o de auxilio, negativas o de exclusión, inmediatamente económicas, remotamente jurídicas, aunque unas y otras relacionadas, concomitantes y recíprocas; pero sin repercusiones exteriores, con personalidad interna, y no de grupo, sino de personas, en confusión el grupo mismo con su órgano representativo. Como la necesidad se repite, coinciden en tal aspecto el Concejo rural y el Concejo de la ciudad. Es más: el de esta última, de seguro, en razôn a su previo estado social, arranca del de aquél; y en cuanto afectando a necesidades económicas que son propias, y no extensivas, logran un sistema de autonomía extraño a la propia organización del Estado. Aquellos Concejos atienden a la riqueza agraria, a la explotación de los bienes comlunales, al aprovechamiento de la dehesa o de los rastrojos, al levantamiento de la cosecha, al servicio del mercado. El Concejo, en suma, salva la vida económica colectiva; pero no es todavía Municipio, aunque pueda llegar a serlo; y de ahí que donde hay grupo, hay Concejo. Las conquistas rompen, desarticulan e interrumpen o desvían la vida propiamente municipal, pero no la concejil, y a través de oleadas de conquistadores, se mantiene la vida común, la concejil, del grupo social, que ha llegado, pese a todas las vicisitudes políticas, e incluso fuera ya de las grandes organizaciones legislativas del Estado, a nuestros días, como pusieron de relieve Costa, Unamuno, Pedregal... y cuantos colaboraron en aquellas memorias, que inició el primero de los citados, sobre Economía popular y derecho consuetudinario de España.

Acaso, no obstante la copiosa literatura, no esté dicho todavía cuanto se desee sobre el Municipio romano; mas de su incorporación 42 a España, de su influencia entre nosotros, bastante es lo conocido y 
puesto de relieve por Pidal, por Hinojosa, por Herculano, por $\mathrm{Da}$ Gama Barros; y aun sin tanto, pues son suficientes a nuestro propósito los más elementales antecedentes, los más generalizados y repetidos ya de tiempo.

Nace el Municipio romano como una consecuencia, guerrera y gubernamental, de la expansión romana, pues en el Municipio encarna el órgano de dominación, enlace al propio tiempo, y de modo recíproco, entre la ciudad imperante y las ciudades dominadas. Así, nace el Municipio, al imponerse un régimen de Estado, justificando aquel concepto de Municipio que formuló Mommisen, y que antes hemos trascrito; pero no con carácter general (tantas ciudades, tantos $\mathrm{Mu}$ nicipios), pues, como se recuerda, se hicieron distintas clasificaciones de las ciudades españolas: libres, federadas, estipendiarias... Y se sabe cuánto se ha discutido sobre la permanencia o interrupción del Municipio romano durante la invasión germánica, según las tesis contrapuestas de Herculano e Hinojosa, y su reaparición posterior.

Dos palabras sobre las cuestiones que quedan enunciadàs. Con la dominación romana desaparecen los anteriores Estados; pero subsisten ciudades y tribus, incluso con su precedente gobierno, reducido, naturalmente, en facultades, comprimido, cercenado; la organización romana crea el Municipio, en forma de colonia, con elementos romanos o latinos, y el Municipium, o ciudad indígena, que por concesión especial ha recibido la ciudadanía o latinidad; unas y otras se organizan de la misma manera, y ya en el siglo I antes de Jesucristo, municipium es toda agrupación urbana con administración autónoma, y acaso unificadas por una ley, si tuvo este carácter general, la uniformadora lex Julia Municipalis, del año 45 antes de Jesucristo.

Entonces Municipio significaba lugar incorporado legalmente a Roma y favorecido con la participación en los cargos y oficios públicos (Munera capiendi), que por regla general reservaban para sí los ciudadanos. (Colmeiro.)

En cuanto al Municipio visigodo, sea lo que quiera de los opuestos criterios que sobre su supervivencia mantuvieron los historiadores a que hemos aludido anteriormente, parece comprobado que sus órganos derivaban del Rey, a quien representaban. Cuando los $\mathrm{Mu}$ nicipios comienzan a nombrar jueces propios, inician su autonomía; mas esta facultad se contiene y se desprende de los fueros, es decir, de las concesiones de los señores, laicos o no, seculares o eclesiás- 
ticos; pero en cualquier caso, creaban una situación tan precaria, transitoria en derecho, y accidental, aunque luego resultara de duración secular, que habían de revalidarse privilegios y exenciones por cada nuevo rey, necesidad ésta tan repetida, que a ella se atrit buye, según parece ser, el extravío de muchos títulos municipales con franquicias y libertades. $\mathrm{La}$ asamblea de vecinos sel suplanta o sustituye por el Ayuntamiento, pero manteniéndose aquélla en las aglomeraciones rurales. Estas quedan en Concejos; aquéllas ascienden a los Ayuntamientos; los Concejos se presiden por los Alcaldes; los Ayuntamientos, por el Corregidor, aunque ni uno ni otro vota, salvo en casos de empate.

Es verdad, e implícitamente queda dicho, que con frecuencia el Municipio, en su aspecto social o como ciudad, se ha formado al margen de Estado, o antes que el Estado, y perdura y, subsiste, aunque el Estado se trastorne, o se modifiquen o cambien radicalmente sus órganos, sentido en el que puede decirse que el Municipio precede al Estado, caso de Norteamérica y mil más; pero cabe también lo más contrario: que el Municipio se cree al tiempo mismo que la ciudad, y aun en rigor antes, ya que el Municipio es una simple declaración jurídica, y la ciudad requerirá de algún tiempo en su edificación y población, caso este repetidísimo, de la colonización de América por España.

En los Estados Unidos las colonias crean los Municipios, bajo la imitación histórica del sistema inglés, salvo, según parece ser, en cuanto a la parroquia. El primitivo gobierno colonial creó el Concejo, aunque también las Compañías, al adquirir tierras de los indígenas, ordenaron los Concejos como un gobierno. $\mathrm{Y}$ cuando, a la inversa, se crean los Estados Unidos, sus instituciones gubernamentales reproducen, para el gobierno total, las de las entidades locales.

Más familiar nos es lo sucedido en la América española. Aquí, como queda apuntado, el Municipio nace incluso antes que la ciudad, y con tales requisitos de formalidad, tan meticulosos, ordenados y dispuestos, que vienen a resultar excepcionales casos, como el de Montevideo, del cual se ignora la fecha de fundación, y aun el de Baracoa, del que se sabe solamente el año, 1512, y el nombre del fundador, Diego Velázquez, pero no el día ni el mes. Lo normal es que todos esos datos se conozcan con toda exactitud. Quito se funda por Diego Almagro en 15 de agosto de 1534, aunque no en su emplazamiento actual; Garay funda Santa Fe en 5 de noviembre de 1573, y Buenos Aires en 11 de junio de 1580. En estos casos nace 44 ya la ciudad-Municipio, mediante acta. El Rómulo español, por lo ge- 
neral un conquistador, por sí mismo o por orden real, elige el emplazamiento según sus propias iniciativas, primero, y luego recibiéndolas de las Leyes de Indias; clava una viga en el suelo, con lo que representa el rollo jurisdiccional, y señala el centro de la plaza y del pueblo; acota el solar para la iglesia y, para la Casa de la Ciudad, delimita los campos de labor, la dehesa, el exido, la parte edificable con sus calles y manzanas de casas; se elige el Concejo con sus $\mathrm{Al}$ caldes, se nombra el escribano, se levanta el acta... He aquí unos párrafos de la de la fundación de Buenos Aires: "Hago e fundo en el dicho asyento e puesto una ciudad, la cual pueblo con los soldados que al presente tengo y e traydo para ello... Por tanto acatando las calidades, avilidad y cristiandad de vos, Rodrigo Ortiz de Garate y Don Gonzalo Mantel de Guzmán, vos señalo e nombro por tales alcaldes hordinarios, y asy mesmo a vos, Pedro de Quéros e Diego de la Varrieta y Antonio Bermudes y Luis Gaytan y Rodrigo de Ibarrola y Alonso de Escobar, por regidores de esta dicha ciudad... Por la presente establezco y mando que los dichos oficios vaquen el día de San Juan de junio del año próximo venidero de 81 , y por la mañana el tal día, antes de mysas mayores, se junten a cabildo los dichos alcaldes e regidores, todos los que oviere e pudieren ser avidos en esta ciudad, e voten e elijan nuevos alcaldes e regidores para el año siguiente... $E$ luego el dicho señor general dixo que en lugar del señor adelantado, el licenciado Juan de Torres de Vera y Aragón, en cumplimiento de lo capitulado de Su Majestad, tomaba e tomo la posesión de la dicha cibdad... y en señal de possession echo mano a su espada y cortó hiervas y tiró cuchilladas..."

Montevideo, anteriormente citado, fué ciudad que se fundó de orden de Felipe $\mathrm{V}$ con veinticinco familias canarias (otras veinticinco. hubieran debido proceder de Galicia, según el proyecto ideado), y Santa Lucía, luego San Juan Bautista, próximas a Montevideo y de la misma época. De esta última se conserva íntegro el expediente, que se comienza en 1781. En todos estos casos, como en muchísimos otros, el Municipio nace a la par de su ciudad por un fiat del Rey. No precisamente del Rey, pero hasta por iniciativa privada, tenemos ejemplos en España mismo; tal el del Nuevo Baztán (por homenaje y diferenciación del Baztán navarro de que procedía el fundador), pueblo conocido de la provincia de Madrid y partido de Alcalá de Henares, con 272 habitantes en la actualidad. Se erigió de planta ciertamente por los años de 1709 a 1713, por don Juan Goyeneche, que creó en él diversas industrias, incluyéndole en su mayorazgo; 
la traza se hizo por José de Churriguera, con calles tiradas a cordel, tejados uniformes y buena plaza mayor. Más reflexiva no pudo ser la creación.

Si un Municipio no siempre corresponde a un pueblo, claro está que el Municipio resultará dividido en su función social, según los grupos urbanos a que afecte. Todo poblado ha de integrar un Municipio; pero como elemiento social componente y determinante, por sí o con otros varios, como en el caso citado del de Pontevedra, La Estrada. Por cierto que, en contraposición a él, recordaremos otro minúsculo y unitario, el más reducido de población que tenemos en España, el de Torviscoso (Cáceres), con solos 48 habitantes en la actualidad $\mathrm{y}$, por lo visto, de poca savia, pues, mediado el siglo pasado, el Diccionario Geográfico de Madoz le atribuía 10 vecinos y 54 almas.

Desde el momento en que no hay correspondencia entre el elemento social, dígase pueblo, ni su unidad logra siempre la personalidad jurídica plena, sino que ésta frecuentemente se integra por varias de aquéllas, con la jurídica, que es el Municipio, derivado del Estado, la consideración del Municipio como entidad natural es inútil, sobre ser inexacta, lógica e históricamente. Las leyes mismas que acogen la naturalidad de estos grupos se refieren luego a la ley como fuente de reconocimiento de aquella personalidad, con lo cual caen en contradicción, pues o es inútil la naturalidad o no ha de precisarse ley complementaria; y si ésta es necesaria, quiere decirse que lo es para todo y que es de ella de quien arranca la personalidad municipal, así como su amplitud y significación.

Y el problema no es sólo de terminología, quiero decir que no se plantea solamente por el hecho de que unos pueblos se llamen $\mathrm{Mu}$ nicipios y otros no, si unos y otros reciben una organización peculiar, pues para todos tiene aplicación la reflexión consignada de que reciben su consideración jurídica de la ley y en la amplitud que la ley fija.

Ahora bien, si el análisis realizado hasta aquí es completo, vendrá a resultar que los elementos que integran un Municipio, para serlo, necesariamente y con necesidad que nada puede salvar, son éstos: uno o varios núcleos urbanos, mayores o menores; unidad jurídica y administrativa, derivada del Estado, en su ordenación, reconocimiento, creación y facultades; un territorio en cuanto campo o ámbito de jurisdicción pública (no privada, pues de esta naturaleza puede un Municipio poseer fuera de sus términos; pero ya sin ju46 risdicción pública, sino solamente como facultad de derecho privado). 
Claro está que toda definición ha de recoger esos elementos para ser completa; si alguno falta, la definición resultará defectuosa. En este sentido, el Municipio podrá definirse en estos términos:

Institución juridicopolítica que personifica, con facultades públicas y capacidad civil, una o varias comunidades de familias, entidades, bienes y trabajo, emplazada en un termino legalmente circunscrito al que extiende su poder jurisdiccional e integrada en el Estado como órgano final de su jerarquía administrativa territorial.

$$
\begin{aligned}
& \text { Recaredo Fernandez de Velasco } \\
& \text { Catedrático de Derecho Administrativo- } \\
& \text { y de la Escuela Nacional de Administra- } \\
& \text { ción y Estudios Urbanos }
\end{aligned}
$$

